\title{
Influence of physical activity on lymphocyte subsets in adolescents from Madrid. The AFINOS Study
}

\author{
A. M. Veses ${ }^{1}$, S. Gómez-Martinez ${ }^{1}$, D. Martinez-Gómez ${ }^{1,2}, \mathrm{O}_{\text {. Veiga }}^{2}$ and A. Marcos ${ }^{1}$ \\ ${ }^{1}$ Immunonutrition Research Group, Department of Metabolism and Nutrition, Institute Frio-ICTAN, Spanish National \\ Research Council (CSIC), Madrid, Spain and ${ }^{2}$ Department of Physical Education, Sport and Human Movement, Facultad \\ de Formación del Profesorado y Educación, Universidad Autónoma de Madrid, Madrid, Spain
}

Many studies have shown that the practice of physical activity (PA) at different intensities modulates functions on different body's defence systems. Thus, evidence based on laboratory settings has shown that PA at moderate intensity protects against infections, whereas a vigorous PA can lead to a decrease in the defensive capacity of the immune system ${ }^{(1)}$.

The aim of this analysis is to evaluate the influence of habitual PA objectively measured by accelerometer on lymphocyte subsets in a sub-sample of AFINOS study (PA as a preventive agent in the development of overweight, obesity, allergies, infections and cardiovascular risk factors in adolescents).

A sub-sample of 196 adolescents from Madrid of 2000 who were enrolled in the AFINOS study was assessed. Total PA and PA at different intensities - light, moderate, vigorous, moderate-to-vigorous were measured by the ActiGraph accelerometer for 7 days. Lymphocyte subset percentages $(\mathrm{CD} 3+, \mathrm{CD} 4+, \mathrm{CD} 8+, \mathrm{CD} 16+56+$ and $\mathrm{CD} 19+)$ were determined by flow cytometry.

No significant differences between genders were found in lymphocyte subsets. Boys had higher levels of total PA, moderate, vigorous and moderate-to-vigorous intensities than girls. Positive correlations between moderate PA and CD3+, light PA and CD4+ and CD3+ were shown in boys together with negative correlations between light PA and CD16 +56 + . However, total, light, moderate and moderateto-vigorous PA values were positively correlated with CD19+ cells in girls.

\begin{tabular}{|c|c|c|c|c|c|c|c|c|c|c|}
\hline \multirow[b]{2}{*}{ Correlation coefficients } & \multicolumn{5}{|c|}{ Boys $(n=99)$} & \multicolumn{5}{|c|}{ Girls $(n=97)$} \\
\hline & $\mathrm{CD} 3+$ & $\mathrm{CD} 4+$ & $\mathrm{CD} 8+$ & $\mathrm{CD} 16+\mathrm{CD}^{2} 6^{+}$ & $\mathrm{CD} 19+$ & $\mathrm{CD} 3+$ & $\mathrm{CD} 4+$ & $\mathrm{CD} 8+$ & $\mathrm{CD} 16+\mathrm{CD} 56+$ & $\mathrm{CD} 19+$ \\
\hline Total PA (counts per minute) & 0.18 & 0.13 & 0.06 & -0.10 & -0.13 & -0.01 & 0.09 & -0.04 & -0.15 & $0.37 * *$ \\
\hline Minutes per day of light PA & $0.25^{*}$ & $0.20 *$ & 0.02 & $-0.22 *$ & -0.03 & -0.04 & 0.03 & 0.04 & -0.06 & $0.26^{*}$ \\
\hline Minutes per day of moderate PA & $0.25^{*}$ & 0.15 & 0.05 & -0.19 & -0.10 & -0.05 & 0.10 & -0.11 & -0.07 & $0.34 * *$ \\
\hline Minutes per day of vigorous PA & 0.01 & 0.06 & -0.02 & 0.07 & -0.16 & 0.07 & 0.06 & 0.16 & -0.11 & 0.07 \\
\hline Minutes per day of moderate to vigorous PA & 0.15 & 0.14 & -0.01 & -0.05 & -0.19 & 0.03 & 0.11 & 0.06 & -0.13 & $0.25^{*}$ \\
\hline
\end{tabular}

$* P<0.05, * * P \leq 0.001$.

We can conclude that the potential effect of PA on lymphocyte subset percentages may be mediated by sex. Specifically, cell-mediated immunity is associated with light and moderate PA intensities in boys; meanwhile, total PA and PA at different intensities are associated with humoral immunity in girls, with the exception of vigorous PA.

1. Timmons BW (2005) Exerc Immunol Rev 11, 108-144. 